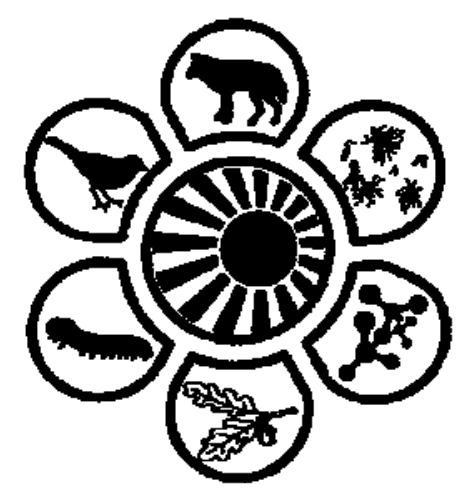

Вісник Дніпропетровського університету. Біологія, екологія.

Vìsnik Dnìpropetrovs'kogo unìversitetu. Seriâ Bìologiâ, ekologiâ

Visnyk of Dnipropetrovsk University. Biology, ecology.

Vìsn. Dnìpropetr. Unìv. Ser. Bìol. Ekol. 2015. 23(2), 172-176.

doi: $10.15421 / 011524$

ISSN 2310-0842 print

ISSN 2312-301X online

www.ecology.dp.ua

УДК 598.115.33(477.54)

\title{
Распространение степной гадюки Vipera renardi (Reptilia, Viperidae) в Харьковской области
}

\author{
А.И. Тупиков ${ }^{1}$, А.И. Зиненко ${ }^{2}$ \\ ${ }^{1}$ Национальный природный парк “Двуречанский”, Двуречное, Украина \\ ${ }^{2}$ Музей природы Харьковского национального университета имени В.Н. Каразина, Харьков, Украина
}

\begin{abstract}
Изучение современного состояния популяций животных, находящихся под охраной, является неотъемлемым элементом в разработке и построении грамотной стратегии охраны видов. Vipera renardi Christoph, 1861 (Reptilia, Viperidae) включена в Красную книгу Украины, а также в Красную книгу Харьковской области и имеет статус уязвимого вида. В статье приведены обобщенные данные о распространении вида в историческом прошлом, а также о современном состояним популяций в Харьковской области, полученные в результате натурных обследований ранее известных и потенциальных местообитаний. Восемьдесят процентов известных до конца $\mathrm{XX}$ века популяций степной гадюки в области исчезли. Вероятнее всего, это связано с преобразованием биотопов и, возможно, другими не выясненными причинами, в числе которых отдаленные эффекты фрагментации популяций, загрязнение и побочные результаты применения ядохимикатов. Гадюки практически отсутствуют в северной, лесостепной части области. Северная граница вида в регионе сместилась к югу и сейчас проходит по северной границе степной зоны. На данный момент в Харьковской области достоверно подтверждено пять местообитаний этого вида. Находки в окрестностях пос. Червона Хвыля и пгт. Шевченково приводятся впервые.
\end{abstract}

Ключевые слова: Vipera renardi; граница ареала; кадастр находок; вымирание

\section{Distribution of the steppe viper Vipera renardi (Reptilia, Viperidae) in Kharkiv region}

\author{
A.I. Tupikov ${ }^{1}$, O.I. Zinenko ${ }^{2}$ \\ ${ }^{I}$ National Nature Park "Dvorichanskiy", Dvorichna, Ukraine \\ ${ }^{2}$ Museum of Nature at V.N. Karazin Kharkiv National University, Kharkiv, Ukraine
}

The up-to-date knowledge on the current state of populations of endangered species is essential for the development of sound species conservation strategy. The steppe viper Vipera renardi Christoph, 1861 (Reptilia, Viperidae) is vulnerable species listed in the Red book of Ukraine and the Red book of Kharkiv region. The article summarizes the historical distribution of the species and the current state of populations within the Kharkiv region. Data about the current state of populations was obtained during full-scale study of all previously known habitats and a number of potential ones. Eighty percent of historical populations known in the region were not confirmed and probably they had become extinct before the end of the XX century. The cause of such decline is unknown since the majority of historically known populations sites remain preserved until now. Among the most probable factors which have led to local extinction are delayed consequences of fragmentation (lost of genetic diversity, small population size which did not allow recovering after reaching the minimum population size during population fluctuations), pollution and side effects of pesticide application. The steppe viper is now absent in the northern forest-steppe part of the region. Thus, the northern border has displaced to the South and now goes along the northern border of the steppe zone. Currently five localities were confirmed within the Kharkiv region. The populations in the suburbs of Chervona Khvylya village and Shevchenkovo town are found by us for the first time.

Keywords: Vipera renardi; anthropogenic range shift; cadastre; extinction

Национальный природный парк “Двуречанский”, ул. Привокзальная, 51, пос. Двуречное, 62701, Украина National Nature Park "Dvorichanskiy”, Privokzalna Str., 51, Dvorichna, 62701, Ukraine

Tel.: +38-050-839-04-51.E-mail: a.i.tupikov@gmail.com

Музей природы Харьковского начионального университета имени В.Н. Каразина, ул. Тринклера, 8, Харьков, 61058, Украина Museum of Nature at V.N. Karazin Kharkiv National University, Trinkler Str., 8, Kharkiv, 61058, Ukraine

Tel.: +38-066-191-08-67. E-mail: zinenkoa@yahoo.com 


\section{Введение}

В прошлом около 40\% территории Украины было представлено степными биогеоценозами. Начиная с 1950-х гг. степи Украины были в значительной мере трансформированы, главным образом в результате тотальной распашки. К настоящему времени только 3\% степей на территории страны сохранилось, значительная часть из них уже не являются целинными, а представляет собой деградировавшие и восстанавливающиеся степные участки. Вследствие этого виды, характерные для указанных биогеоценозов, оказались на грани исчезновения, а их ареалы сильно сократились (Borozenec and Foroshhuk, 1998; Vasiljuk, 2009, 2013; Hanski, 2010; Reading et al., 2010; Pakhomov et al., 2011).

Харьковская область в природно-климатическом отношении неоднородна: северная, центральная и западная ее части расположены в лесостепной зоне, а южная и восточная - в степи (Barbarych, 1977). При этом мозаичность лесостепных ландшафтов позволяла степной фауне проникать вглубь лесостепной зоны вплоть до северной ее границы. Степные виды, однако, находятся в лесостепи в субоптимальных условиях и здесь более уязвимы, исчезая вследствие даже незначительных внешних воздействий.

Степная гадюка Vipera renardi (Christoph, 1861) является единственным представителем степной офидиофауны Харьковской области в настоящее время. Изучение экземпляров, хранящихся в коллекции Музея природы Харьковского национального университета им. В.Н. Каразина (Vedmederja et al., 2007), и литературных источников (Pengo, 1870; Sukhow, 1928) показало, что еще в начале XX в. степная гадюка обитала на территории всего указанного региона. Однако начиная с 1980-х годов практически перестает поступать информация о находках этого вида, что только отчасти можно объяснить спадом интенсивности исследований.

Целью нашего исследования было обобщить разнородные данные и выяснить современное распространение и тренд численности степной гадюки на территории Харьковской области. Исходя из этого, в задачи исследований входило 1) обследовать существовавшие ранее популяции степной гадюки; 2) провести поиск новых мест обитания этого вида на ранее не обследованных сохранившихся степных участках.

\section{Материал и методы исследований}

Обобщены источники, в которых содержатся сведения об обитании степной гадюки в Харьковской области: коллекции Музея природы ХНУ им. В.Н. Каразина, литературные данные и надежные персональные сообщения (поступившие от квалифицированных респондентов). Начиная с 2000 г. мы проводили собственные полевые исследования. Все известные локалитеты перепроверены нами наряду с потенциальными местообитаниями в полевые сезоны 2014-2015 гг. Гадюк учитывали во время маршрутных учетов (Shherbak, 1989) во время сезона активности, преимущественно весной, в начале лета и осенью, в светлое время суток, исходя из сущест- вующих представлений о сезонной и суточной активности вида (Shherbak, 1966; Kotenko, 1981; Karmyshev, 1999; Pavlov, 2003).

Координаты точек находок определяли при помощи GPS-навигатора. Для большинства находок конца $\mathrm{XX}$ века музейные этикетки дополнительно уточняли у сборщиков. Координаты в таком случае определяли при помощи программ Google Maps, Google Earth и Ozzi Explorer. Карта распространения (рис. 1) генерирована в программе Quantum GIS.

\section{Результаты и их обсуждение}

В таблице приводятся сведения о всех известных и наиболее вероятных находках степной гадюки на территории Харьковской области. Исследования современного состояния распространения степной гадюки на территории области показало сильное сокращение числа мест обитаний. Из десяти известных до 2000-х гг. популяций к настоящему времени нами подтверждено существование лишь двух (№ 4 и 9 из табл.). В ходе исследований обнаружены еще три ранее не задокументированные популяции степной гадюки (№ 10 и 12 из табл.). Таким образом, на современном этапе в Харьковской области достоверно известно о пяти местах обитания степной гадюки (рис.).

Несмотря на то, что для большинства исторически известных популяций степной гадюки в Харьковской области биотопы сохранились, достоверные причины потери мест обитания остаются неизвестными. Стоит отметить, что тенденция в общем снижении количества мест обитания змей наблюдается и в других странах (Reading et al., 2010), где причины сокращения также неясны.

В числе возможных и наиболее вероятных примеров факторов, сокращающих ареал обитания степной гадюки в Харьковской области, мы отметим следующие.

1. Изменение качества среды обитания вида. К этой категории относятся самые разнообразные по своему воздействию и масштабности факторы. Например, традиционно сложившиеся среди местного населения в последние десятилетия весенние и осенние палы сухой и прошлогодней растительности. В результате этого происходит не только общее ухудшение параметров биотопа, но и сукцессия травянистых сообществ (Shalyt and Kalmykova, 1935; Malysheva and Malahovskij, 2000; Fischer and Lindenmayer, 2007; Timoshenkov and Timoshenkova, 2007; Reading et al., 2010).

К числу негативных факторов стоит отнести также применение в сельскохозяйственном производстве ядохимикатов и проблему несанкционированных свалок мусора. Так, по данным, предоставленным Государственной фитосанитарной службой Украины, на территории Харьковской области за период 1990-2000 гг. использовано 24 429,4 тыс. т различных пестицидов, что в 3,3 раза больше объемов аналогичного использования в Полтавской области, где объемы применяемых пестицидов составили 7 437,6 тыс. т. Указанные факторы оказывают лишь опосредованное воздействие на рептилий, влияя на продолжительность жизни и репродуктивные способности (Pauli et al., 2010). 
Кадастр сведений о находках степной гадюки на территории Харьковской области

\begin{tabular}{|c|l|l|}
\hline № & \multicolumn{1}{|c|}{ Локалитет } & \multicolumn{1}{c|}{ Источник (год) } \\
\hline 1 & Окр. г. Харьков (Сокольники) & Коллекции МП ХНУ: инв. № 28820 (1827); инв. № 28852 (1918) \\
\hline 2 & Волчанский район, ур. Пивное & $\begin{array}{l}\text { Коллекции МП ХНУ: инв. № 28836 (1965); инв. № 28856 (1966); } \\
\text { инв. № 28827, 28819, 27065 (1968); инв. № 28826 (1970); инв. № 27034 (1973) }\end{array}$ \\
\hline 3 & $\begin{array}{l}\text { Боровской район, } \\
\text { окр. с. Пески Радьковские }\end{array}$ & Коллекции МП ХНУ: инв. № 27617 (1974) \\
\hline 4 & $\begin{array}{l}\text { Изюмский район, } \\
\text { окр. с. Лысогорка, берег р. Сев. Донец }\end{array}$ & Коллекции МП ХНУ: инв. № Г-965 (1998) \\
\hline 5 & Балаклейский район, ст. Сезонная & $\begin{array}{l}\text { Коллекции МП ХНУ: инв. № 28832, 28844, 28848 (1968); инв. № 28840 } \\
\text { (1969); инв. № 28851 (1969); инв. № 28838 (1970); инв. № 28855 (1971); } \\
\text { инв. № 27677, 28857, 28846 (1973); инв. № 27681, Г-150 (1975) }\end{array}$ \\
\hline 6 & Балаклейский район, окр. с. Залиман & $\begin{array}{l}\text { Коллекции МП ХНУ: инв. № 14794, 28823 (1969); инв. № 28822, 27091, } \\
\text { 27033, 27047, 28854 (1973) }\end{array}$ \\
\hline 7 & Балаклейский район, окр. с. Меловая & Коллекции МП ХНУ: инв. № 28850 (1973) \\
\hline 8 & Змиевский район, окр. с. Борки & Коллекции МП ХНУ: инв. № Г-1328 (1977) \\
\hline 9 & $\begin{array}{l}\text { Красноградский район, } \\
\text { окр. г. Красноград }\end{array}$ & Sикһош, 1928 \\
\hline 10 & $\begin{array}{l}\text { Двуречанский район } \\
\text { (окр. с. Тополи, Каменка, Красное-2) }\end{array}$ & Личное сообщение А.Б. Громаковой (2003) \\
\hline 11 & $\begin{array}{l}\text { Великобурлуцкий район, } \\
\text { окр. с. Червона Хвыля }\end{array}$ & Сведения местных жителей (начало 2000-х) \\
\hline 12 & $\begin{array}{l}\text { Шевченковский район, } \\
\text { окр. пгт. Шевченково }\end{array}$ & Сведения местных жителей (начало 2000-х) \\
\hline 13 & $\begin{array}{l}\text { Богодуховский уезд, } \\
\text { Харьковская губерния }\end{array}$ & Коллекции МП ХНУ: инв. № 28825 (1905) \\
\hline
\end{tabular}

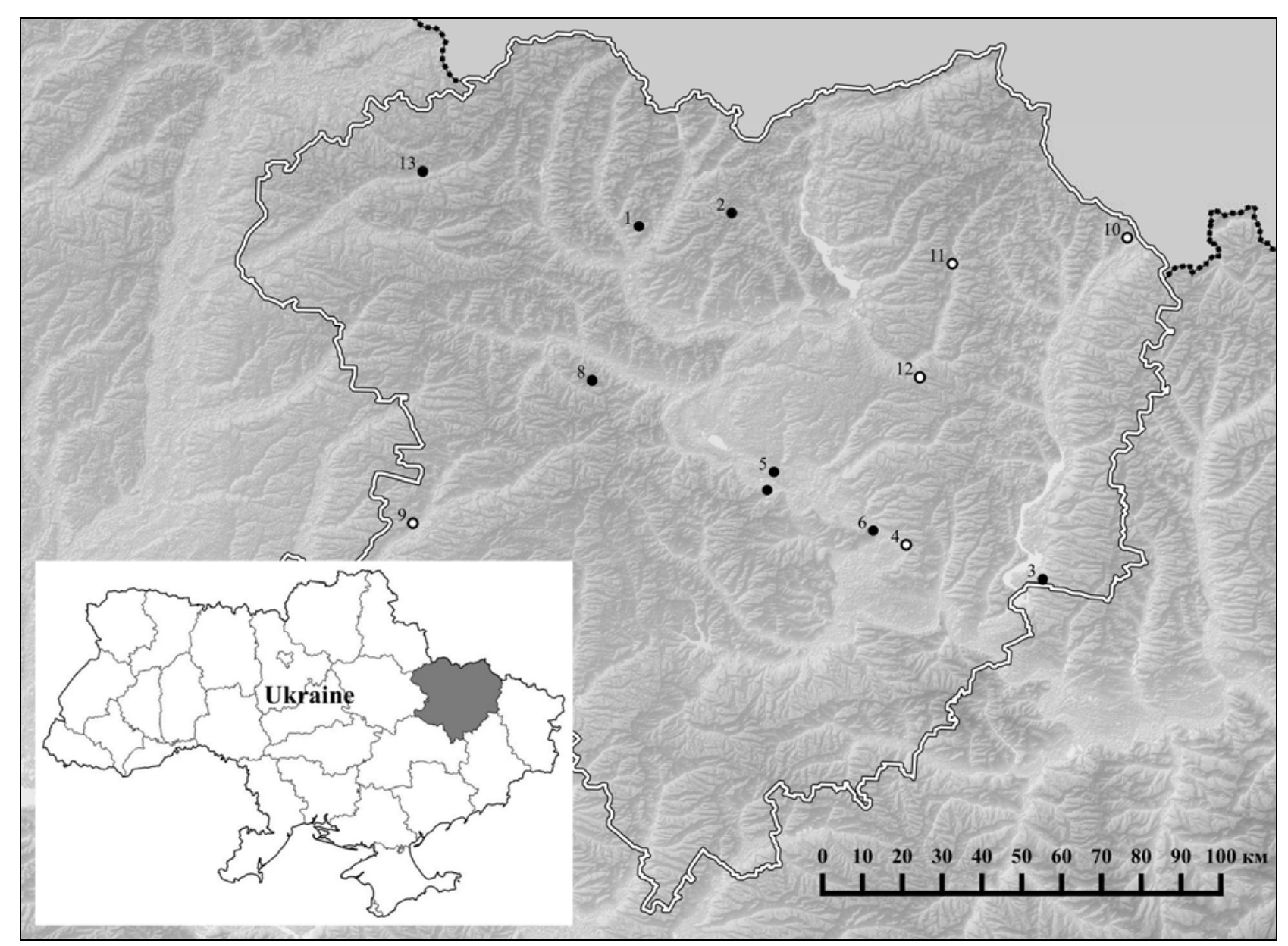

Рис. 1. Современное распространение степной гадюки в Харьковской области:

- - исторически известные до 1980-х гг. популяции, о - существующие популяции; номера точек соответствуют порядковому номеру локалитета в таблице 
2. Сокращчение количества мест обитания из-за хозяйственной деятельности человека. На современном этапе пригодные для жизни степной гадюки биотопы в Харьковской области представляют собой неудобные для ведения сельскохозяйственной деятельности территории: деградированные и восстанавливающиеся остатки степей в балках и оврагах вдоль русел рек, пойменные луга, опушки небольших байрачных лесов, участки разреженного древостоя на склонах, в старых садах, а также на песчаных террасах речных долин в разреженных сосняках и лесополосах. Продолжающаяся потеря местообитаний в настоящее время происходит главным образом из-за нецелевого использования земельных участков (незаконная распашка сенокосов и пастбищ, бесконтрольное увеличение площади пахотных земель за счет самозахвата соседних территорий) и расширение площади населенных пунктов.

3. Инбридинг. Два вышеуказанных комплекса факторов становятся причиной фрагментации и частичной или полной изоляции популяций, что, в свою очередь, приводит к ее дальнейшему генетическому обеднению и постепенному вырождению (Madsen et al., 1996; Újvári et al., 2002).

\section{Выводы}

Проведенное исследование состояния популяции степной гадюки в Харьковской области позволяет сделать следующие выводы:

- число известных до конца XX века популяций степной гадюки сократилось в пять раз;

- хозяйственная деятельность человека оттеснила сохранившиеся популяции на неудобья и вторичные местообитания: залежи и остатки степей, сохранившиеся в оврагах и балках, вдоль крупных речных долин, разреженные леса боровой террасы и остепненная пойма;

- для ряда исторических популяций отмечено исчезновение гадюк при относительно неплохой сохранности самих степных биоценозов, что может указывать на другие причины вымирания (отдаленные эффекты фрагментации популяций, загрязнение, воздействие ядохимикатов);

- для сохранения оставшихся популяций степной гадюки необходима разработка стратегии охраны вида, включающая, в том числе, определение роли других факторов и разработки мер, направленных на их нейтрализацию, и создание в оставшихся местообитаниях природно-заповедных территорий.

\section{Благодарности}

Авторы благодарны своим старшим коллегам А.М. Рудику и Д.Г. Стрелкову за подробные описания мест находок степной гадюки в 1960-1970-е годы, а также А.Б. Громаковой, В.А. Токарскому, О.А. Новикову за информацию о находках гадюк, А.В. Коршунову, А.А. Атемасову, М.О. Высочину за помощь в проведении полевых исследований.

Работа выполнена при поддержке РФФИ, проект 1535-50221 мол_нр, и частично при поддержке The Rufford Small Grants Foundation (RSG reference - 14742-1).

\section{Библиографические ссылки}

Barbarych, A.I., 1977. Geobotanichne rajonuvannja Ukrai'ns'koi' RSR [Geobotanical zoning of Ukrainian SSR]. Naukova Dumka, Kyiv (in Ukrainian).

Borozenec, V.A., Foroshhuk, V.P., 1998. Konceptual'nye voprosy sohranenija stepnyh jekosistem [The conceptual questions of the steppe ecosystems' conservation]. Mat. Mizhnar. Nauk. Konf. Prysv. 100-richchju zap. Askanijs'kogo stepu. Aktual'ni pytannja zberezhennja ta vidnovlennja stepovyh ekosystem. Askanija-Nova. 158-160 (in Russian).

Gasso, V.J., 1998. Ispol'zovanie massovyh vidov presmykajushhihsja dlja biomonitoringa sostojanija okruzhajushhej sredy $\mathrm{v}$ zapovednikah [The use of mass species of reptiles for biomonitoring of the environment in protected areas]. Mat. Mizhnar. Nauk. Konf. Prysv. 100-richchju zap. Askanijs'kogo stepu. Aktual'ni pytannja zberezhennja ta vidnovlennja stepovyh ekosystem. Askanija-Nova. 255-257 (in Russian).

Gibbons, J.F., Scott, D.E., Ryan, T.J., Buhlmann, K.A., Tuberville, T.D., Metts, B.S., Greene, J.L., Mills, T., Leiden, Y., Poppy, S., Winne, C.T., 2000. The global decline of reptiles, déjà vu amphibians. www.bioscience.oxfordjournals.org/ content/50/8/653.full.pdf + html

Hanski, I., 2010. Uskol'zajushhij mir: Jekologicheskie posledstvija utraty mestoobitanij [The shrinking world: Ecological consequences of habitat loss]. KMK, Moskva (in Russian).

Hanski, I., 2011. Habitat loss, the dynamics of biodiversity, and a perspective on conservation. Ambio 40(3), 248-255.

Karmyshev, J.V., Pisanec, E.M., Sirenko, V.A., Sirenko, N.M., 1999. Materialy po sezonnoj aktivnosti stepnoj gadjuki ( $\mathrm{Vi}$ pera ursinii renardi Christ., 1861) na juge Ukrainy [The data of season activity of Steppe viper (Vipera ursinii renardi Christ., 1861) on the South of Ukraine]. Branta, Melitopol'. 63-64 (in Russian).

Kotenko, T.I., 1981. O stepnoj gadjuke na juge Ukrainy [About Steppe viper on the South of Ukraine]. Pjataja Vsesojuz. Gerpetol. Konf. Nauka, Leningrad. 73 (in Russian).

Madsen, T., Stille, B., Shine, R., 1996. Inbreeding depression in an isolated population of adders Vipera berus. Biol. Conserv. 75(2), 113-118.

Malysheva, G.S., Malahovskij, P.D., 2000. Pozhary i ih vlijanie na rastitel'nost' suhih stepej [Fires and their influence on the vegetation of dry steppe]. Botanicheskij Zhurnal 85(1), 96-103 (in Russian).

Pakhomov, O.Y., Gasso, V.Y., Goloborodko, K.K., Poljakov, M.V., Grycan, Y.I., Bulakhov, V.L., Brygadyrenko, V.V., Kljuchko, Z.F., Mezhzherin, S.V., Novicky, R.O., Pysanec, Y.M., Pljushh, I.G., Ponomarenko, O.L., Puchkov, O.V., Radchenko, V.G., 2011. Chervona knyga Dnipropetrovskoi oblasti. Tvarynnyj svit [The red book of Dnipropetrovsk region. Animals]. New Print, Dnipropetrovsk (in Ukrainian).

Pauli, D.B., Linder, G., Bishop, C.A., Krest, S.K. (ed.), 2010. Exotoxicology of amphibians and reptiles. Setac, Pensacola.

Pavlov, A.V., 2003. Sezonnye javlenija v zhizni stepnoj gadjuki (Vipera ursinii) v krajnej severnoj tochke ee obitanija [Seasonal phenomena in the life of Steppe viper (Vipera ursinii) in the very north point of its distribution]. Zmei Vostochnoj Evropy. Mat. Mezhdunar. Konf. 63-65 (in Russian).

Pengo, K.K., 1870. O rodovyh i vidovyh priznakah gadjuki $P e-$ lias (Vipera Daud.) berus Merrem, s dvumja raznostjami: a) pestroj (Pelias (Vipera Daud.) berus Merrem varietas varia) i b) odnocvetnoj ili chernoj (Pelias (Vipera Daud.) berus Merrem varietas nigra) [About family and species features of viper Pelias (Vipera Daud.) berus Merrem, with two differences: a) motley (Pelias (Vipera Daud.) berus Merrem varietas varia) and b) one-coloured or black (Pelias (Vipera Daud.) berus Merrem varietas nigra)]. Tr. Har'kov. O-va Ispyt. Prir. 2, 1-26 (in Russian). 
Reading, C.J., Luiselli, L.M., Akani, G.C., Bonnet, X., Amori, G., Ballouard, J.M., Filippi, E., Naulleau, G., Pearson, D., Rugiero, L., 2010. Are snake populations in widespread decline? www.rsbl.royalsocietypublishing.org/content/early/2010/06/0 3/rsbl.2010.0373.short

Santos, X., Brito, J.C., Sillero, N., Pleguezuelos, J.M., Llorente, G.A., Fahd, S., Parellada, X., 2006. Inferring habitatsuitability areas with ecological modelling techniques and GIS: A contribution to assess the conservation status of $\mathrm{Vi}$ pera latastei. Biol. Conserv. 130(3), 416-425.

Shalyt, M.S, Kalmykova, A.A., 1935. Stepnye pozhary i ih vlijanie na rastitel'nost' [Steppe fires and their influence on vegetation]. Botanicheskij Zhurnal 20(1), 100-110 (in Russian).

Shherbak, N.N. (ed.), 1989. Rukovodstvo po izucheniju zemnovodnyh i presmykajushhihsja [Manual book on research of amphibians and reptiles]. Kiev (in Russian).

Shherbak, N.N., 1966. Zemnovodnye i presmykajushhiesja Kryma Herpetologia Taurica [Amphibians and reptiles of Crimea. Herpetologia Taurica]. Naukova Dumka, Kiev (in Russian).

Sukhow, G.F., 1928. Materijaly do vivchennja gerpetofauni Poltavshhini [The data about research of reptiles' fauna of Poltava region]. Zb. Poltav. Derzh. Muzeju, Poltava. 1, 251256 (in Ukrainian).

Timoshenkov, V.A., Timoshenkova, V.V., 2007. Pozhary v Homutovskoj stepi: Prichiny, informacija, posledstvija [Fires in the Khomutovskyi steppe: Causes, information, effects]. Stepnoj Bjulleten' 23-24, 27-30 (in Russian).

Tokars'kyj, V.A. (ed.), 2013. Chervona knyga kharkivs'koi' oblasti. Tvarynnyj svit [The Red list of Kharkov region. Fauna]. Kharkiv (in Ukrainian).
Újvári, B., Madsen, T., Kotenko, T., Olsson, M., Shine, R., Wittzell, H., 2002. Low genetic diversity threatens imminent extinction for the Hungarian meadow viper (Vipera ursinii rakosiensis). Biol. Conserv. 105(1), 127-130.

Vasiljuk, A.V., 2009. Obshhestvennaja kampanija «Sohranim ukrainskie stepi!» Hronika pervogo polugodija [Social campaign "Save Ukrainian steppes!" The cronicles of first 6 months]. Stepnoj Bjulleten' 27, 26-29 (in Russian).

Vasiljuk, A.V., Kolomycev, G.K., Krivohizhaja, M.V., 2013. Geobotanicheskie okruga Vostochnoj Ukrainy otlichajutsja po sohrannosti stepej [Geobotanic districts of Eastern Ukraine are different because of the steppe preservation]. Stepnoj Bjulleten' 38, 9-12 (in Russian).

Vedmederja, V.I., Zinenko, A.I., Goncharenko, L.A., 2007. Katalog kollekcij Muzeja prirody Har'kovskogo nacional'nogo universiteta im. V.N. Karazina. Zmei (Reptilia: Serpentes) [Catalogue of the collections of the Museum of Nature at V.N. Karazin Kharkiv National University. Reptiles (Reptilia: Serpentes)]. Khar'kov (in Russian).

Zinenko, A.I., Bakiev, A.G., 2007. Ob izmenenii severnoj granicy areala stepnoj gadjuki, Vipera renardi (Reptilia, Viperidae), v evropejskoj chasti Rossii [About the displace of the northern border of the areal of Steppe viper, Vipera renardi (Reptilia, Viperidae), in the European part of Russia]. Vestn. Zool. 41(5), 478 (in Russian).

Надійшла до редколегії 30.07.2015 